\title{
An Approach to the Estimation of Effective Vaporization Enthalpies of Polycyclic Aromatic Hydrocarbons on Particle Surfaces
}

\author{
Richard E. Cochran, Alena Kubátová, Evguenii I. Kozliak \\ University of North Dakota, Department of Chemistry, Grand Forks, ND, USA \\ SUPPORTING INFORMATION
}

\section{Table of Contents}

Figure S1. Example DSC heat flow curves for phenanthrene using different aluminum cup configurations as well as an SEM image of the pierced hole of the sample cup lid.

Figure S2. TGA thermograms along with linearization results from the integral and derivative methods obtained from the analysis of neat standards of 3-4 ring PAHs.

Figure S3. TGA thermograms and DSC heat flow curves obtained for neat standards of 3-4 ring PAHs.

Figure S4. SEM images of anthracene spiked to particle surfaces. 
Figure S1. a) DSC heat flow curves obtained for phenanthrene standard when using different configurations of the aluminum sample cup during TGA-DSC analysis. Analysis was performed using a linear oven heating rate of $20{ }^{\circ} \mathrm{C} / \mathrm{min}$ and a purgae gas $\left(\mathrm{N}_{2}\right)$ flow rate of $20 \mathrm{~mL} / \mathrm{min}$. b) Scanning electron microscopy (SEM) image of the hole pierced into the lid of an aluminum sample cup.

a)

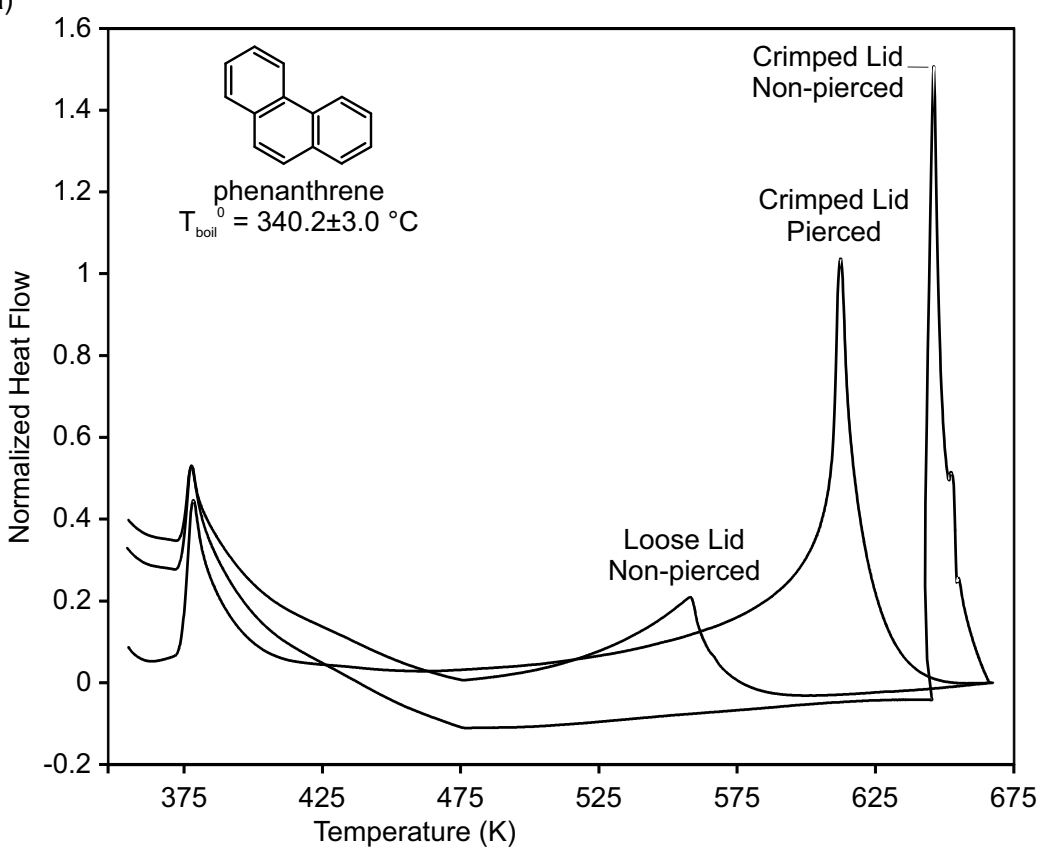

b)

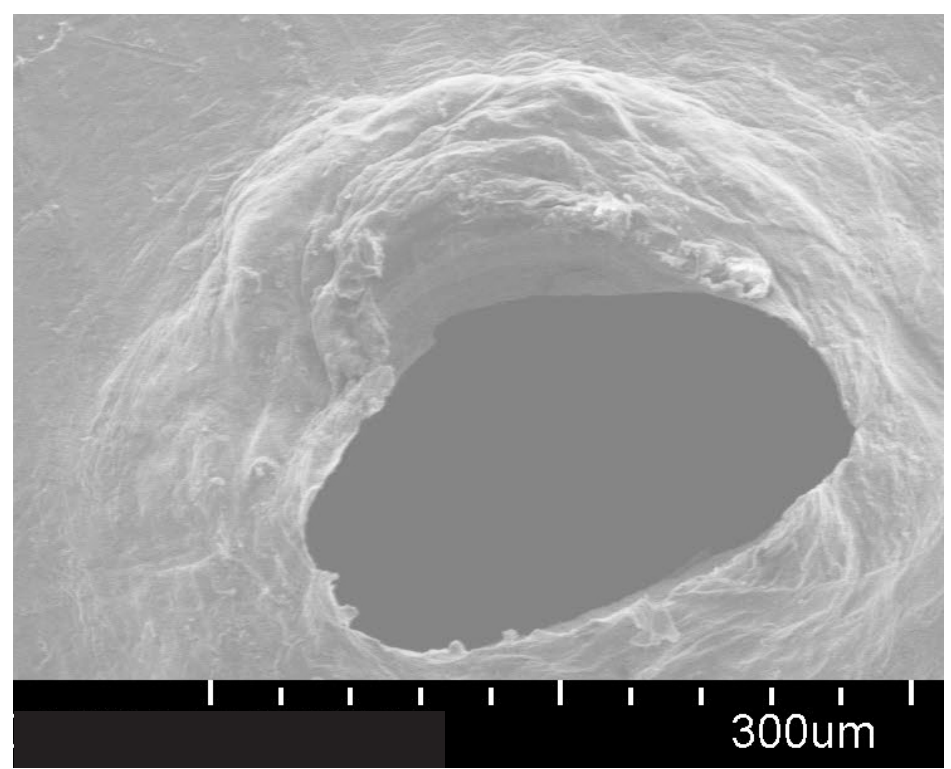


Figure S2. TGA thermograms and linearization results for both the integral method (left) and derivative method (right) when analyzing neat standards of 2-4 ring PAHs. For the resulting curves of the linearization methods the range used for calculating $\Delta \mathrm{H}_{\mathrm{vap}}$ are shown.
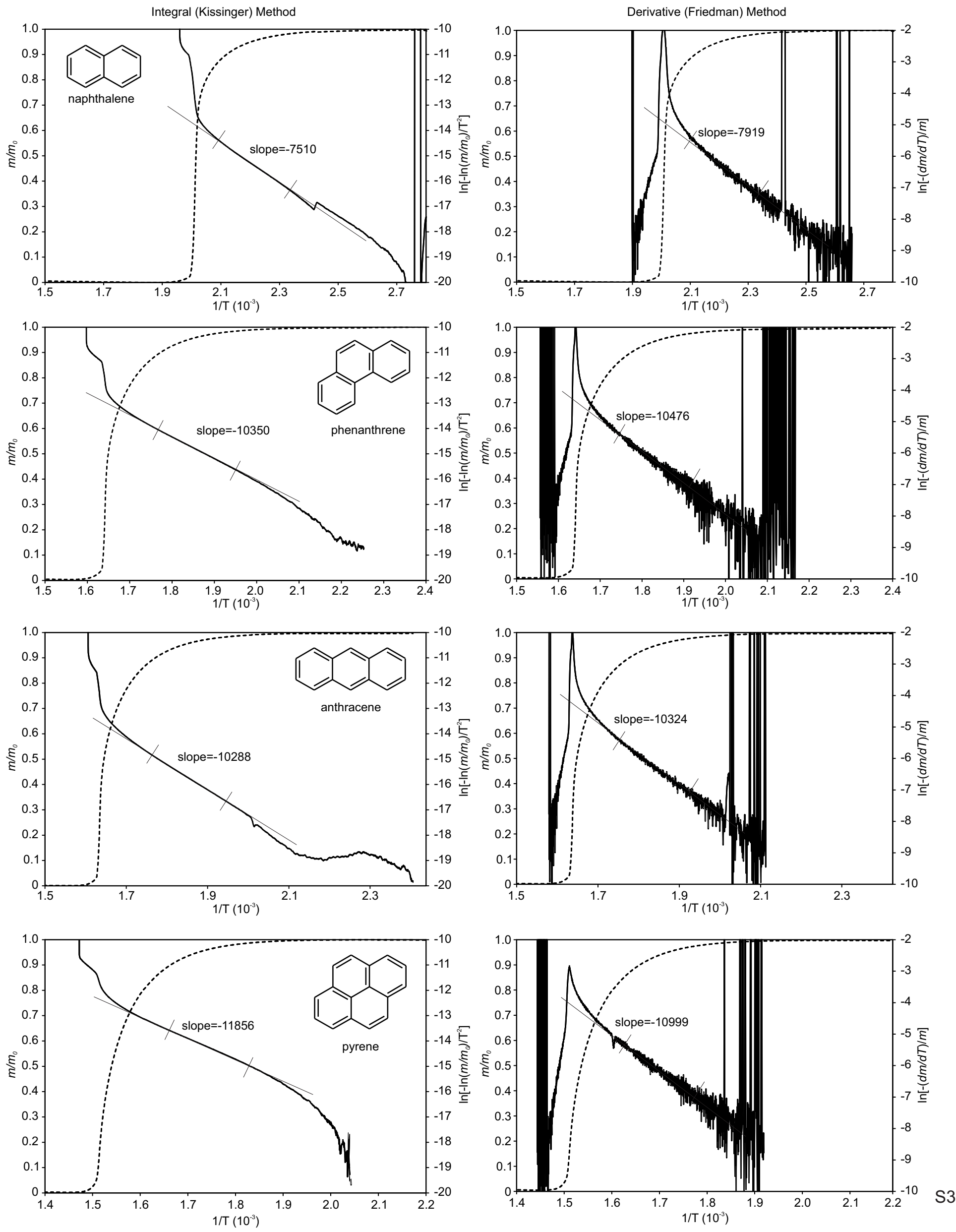
Figure S3. TGA thermograms and DSC heat flow curves (left) along with DTG differential mass loss rate curves (right) obtained during the analysis of neat standards of 2-4 ring PAHs. Analysis was performed using a linear oven heating rate of $20^{\circ} \mathrm{C} / \mathrm{min}$ and a purgae gas $\left(\mathrm{N}_{2}\right)$ flow rate of $20 \mathrm{~mL} / \mathrm{min}$.
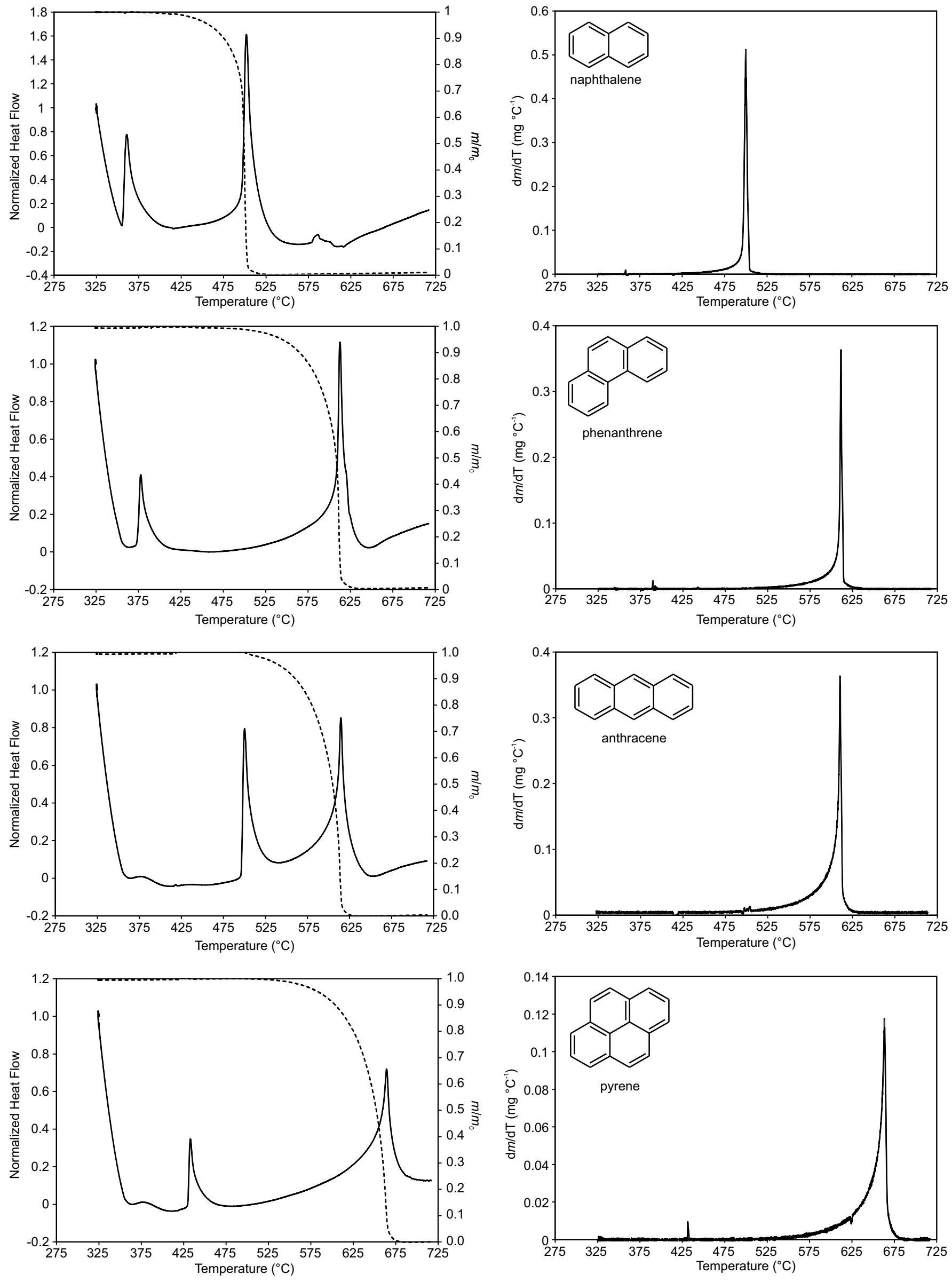
Figure S4. Scanning electron microscopy (SEM) images of anthracene spiked to different particles surfaces: a) silica, b) graphite and c) graphene. Anthracene was identified by comparing images with blank particle to those spiked with anthracene.

a)

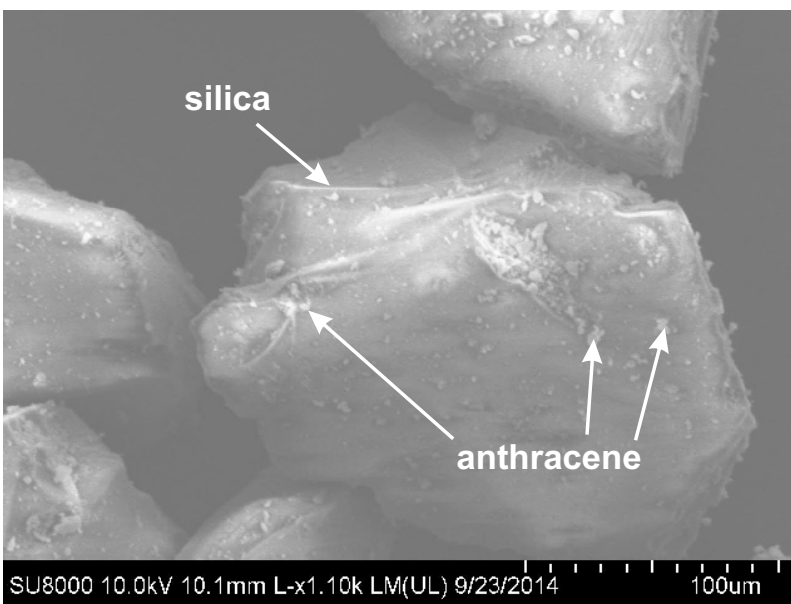

b)

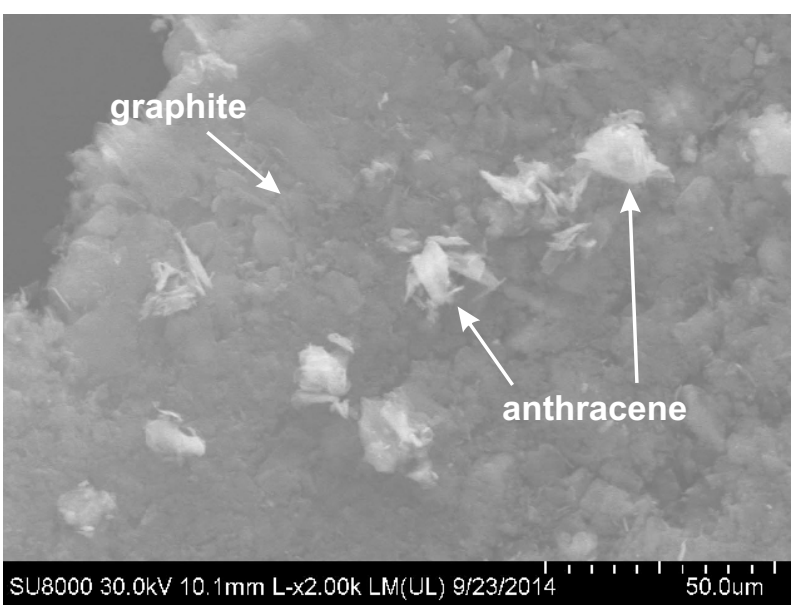

c)

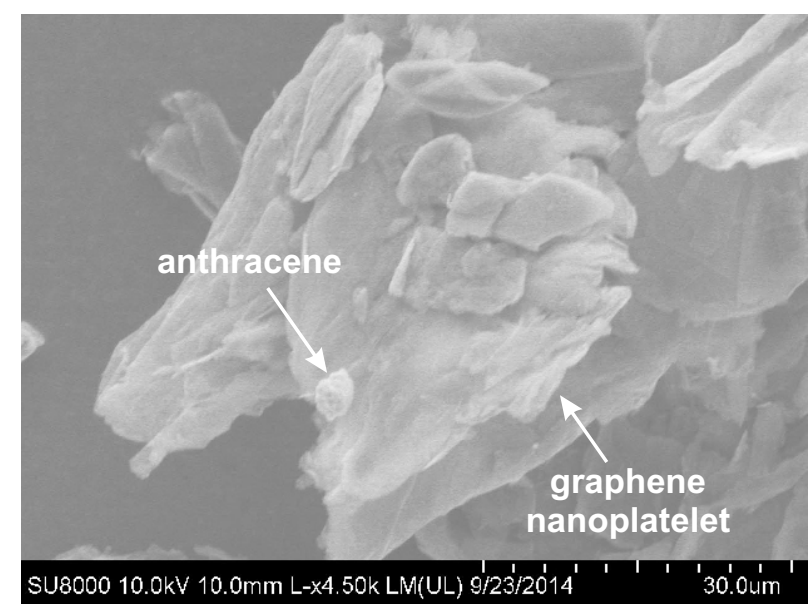

